\title{
Valoración del dolor en los pacientes en hemodiálisis
}

\author{
Mónica Brazález Tejerina, Cristina Franco Valdivieso, Susana Merino Hernansanz
}

Hospital Clínico Universitario. Valladolid

\section{Introducción:}

El dolor es un síntoma frecuente y multidimensional que podemos encontrar en las unidades de hemodiálisis (HD), con difícil valoración por parte del personal de enfermería debido a la subjetividad del mismo. El paciente sometido a HD, lleva asociada a su enfermedad una gran comorbilidad que a menudo no es valorada en su totalidad, ni las limitaciones que les ocasionan en su calidad de vida.

\section{Objetivo:}

Valorar el dolor crónico que padecen los pacientes de nuestras unidades, tanto dentro como fuera de las sesiones de HD.

\section{Material y métodos:}

Estudio descriptivo prospectivo en el que se incluyeron a 23 pacientes de dos unidades de HD (9 hombres y 14 mujeres) de edad media de 63,22 años. Entre las patologías más comunes en nuestra muestra encontramos: diabetes mellitus y cardiopatías isquémicas. La media de tiempo en tratamiento con HD fue de 4,51 años siendo su duración media entre 3:30-4 horas por sesión. Los diferentes parámetros analizados fueron: intensidad, localización e influencia del dolor en las actividades de la vida diaria. Se aplicaron dos escalas validadas Escala Visual Analógica (EVA) y el BriefPainInventory (BPI) y una encuesta socio demográfica, durante la última hora de la HD.

\section{Resultados:}

En el $91,31 \%$ de los pacientes encuestados se observó un dolor de intensidad leve a moderado en el momento de pasar las encuestas. (EVA) EI 82,61\% de los pacientes encuestados tuvieron dolor durante las últimas 24 h, con una media de intensidad máxima de 6'34 sobre 10 y de mínima 3,26 sobre 10 . Se observó que el dolor era más frecuentemente de carácter osteoarticular, localizándose predominantemente en la región sacrococcígea y en las extremidades tanto superiores como inferiores. El 30,43\% de los pacientes encuestados no tenían tratamiento analgésico pautado. En la mayoría de los casos realizaron cambios posturales o distracciones para su alivio. $Y$ entre los que tenían analgesia pautada, el paracetamol fue el fármaco más empleado para aliviar su sintomatología, siendo su efectividad máxima del $61,42 \%$. Con relación a las actividades diarias, se observó que el dolor no influyó de manera significativa en la capacidad de caminar, en el trabajo, en la capacidad de diversión, en la relación con otras personas, en el estado de ánimo y en el sueño. El 82,61\% pacientes consideró que el personal de enfermería valora adecuadamente el dolor que padece durante las sesiones de hemodiálisis.

\section{Conclusiones:}

A pesar de que el trabajo se diseñó a partir de las quejas verbales de nuestros pacientes, el estudio muestra una menor prevalencia del dolor de la inicialmente esperada. Consideramos que el personal enfermero debería adoptar una actitud proactiva e integral en la prevención del dolor, valorando sus 
características para conseguir un plan de cuidados individualizado. Aunque se hayan utilizado escalas validadas, es posible que no se ajusten con exactitud a las necesidades valorativas del paciente en HD, siendo necesaria la creación de escalas más específicas para nuestro ámbito.

\section{Referencias Bibliográficas}

1. Valoración del dolor en los pacientes en hemodiálisis. M M Pastor Armendáriz, et al. RevSocEspEnfermNefrol 2010; 13 (4): 264/266.

2. Evaluación y manejo del dolor intradiálisis. Rodríguez Calero, MA et al. RevSocEspEnfermNefrol 2006; 9 (2): 65/70.

3. Diferencias entre dolor intradiálisis y dolor crónico en Pacientes hemodializados. D Hernández Sánchez et al. 